\title{
Study and Simulated the Natural Radioactivity (NORM) U-238, Th-232 and K-40 of Igneous and Sedimentary Rocks of Al-Atawilah (Al-Baha) in Saudi Arabia
}

\author{
Bashayer M. Al-Zahrani1 ${ }^{*}$, Haifa S. Alqannas ${ }^{2}$, Safia H. Hamidalddin² \\ ${ }^{1}$ Physics Department, Faculty of Science, Al Baha University, Al Baha, Saudi Arabia \\ ${ }^{2}$ Physics Department, Faculty of Science, University of Jeddah, Jeddah, Saudi Arabia \\ Email: ^bmsalzahrani@bu.edu.sa
}

How to cite this paper: Al-Zahrani, B.M., Alqannas, H.S. and Hamidalddin, S.H. (2020) Study and Simulated the Natural Radioactivity (NORM) U-238, Th-232 and K-40 of Igneous and Sedimentary Rocks of Al-Atawilah (Al-Baha) in Saudi Arabia. World Journal of Nuclear Science and Technology, 10, 171-181.

https://doi.org/10.4236/wjnst.2020.104015

Received: September 11, 2020

Accepted: October 18, 2020

Published: October 21, 2020

Copyright $\odot 2020$ by author(s) and Scientific Research Publishing Inc. This work is licensed under the Creative Commons Attribution International License (CC BY 4.0).

http://creativecommons.org/licenses/by/4.0/

\begin{abstract}
In this work, gamma-ray spectroscopy based on semiconductor hyper pure germanium (HPGe) detector was used to evaluate the activity concentrations of the natural radionuclides (U-238 (Ra-226), Th-232 and K-40) and the fallout nuclide (Cs-137) for thirty samples of igneous and sedimentary rocks of Al-Atawilah (Al-Baha). The mean values of the activity concentrations of U-238 (Ra-226), Th-232, K-40 and Cs-137 in the igneous samples are found as $(11.0,11.50,1172.71,1.47) \mathrm{Bq} / \mathrm{Kg}$ respectively. In the sedimentary rocks, the mean values of the activity concentrations of the natural radionuclides (U-238 (Ra-226), Th-232 and K-40) and the fallout nuclide (Cs-137) equal to $(12.04,13.18,1131.36,1.60) \mathrm{Bq} / \mathrm{Kg}$ respectively. The averages of radiological hazards $\left(R a_{e q}, H_{e x}\right.$ and $\left.I_{\gamma}\right)$ were calculated and found to be within the UNSCEAR permissible limit values ( $370 \mathrm{~Bq} / \mathrm{kg}$ for $R a_{e q}$ and 1 for $H_{e x}$ and $I_{\gamma}$ ), except for a slight increase of average value of $I_{\gamma}$ in the igneous rock samples (1.36). The results indicate that the dose rate values depend on the kind of rocks (high in some igneous rock samples, and most of sedimentary rock samples have low dose rate). The activities of naturalnuclides were predicted and simulated in T time using a written MATLAB R2020a script based on the average activity concentrations and respective half-lives of U-238 and Th-232 series, and $\mathrm{K}-40$, this is to evaluate the future effects of natural radionuclides on the population and estimate the human inputs in the future.
\end{abstract}

\section{Keywords}

Natural Radioactivity, Gamma-Ray Spectroscopy, Activity Concentration, Igneous and Sedimentary Rocks, Simulated in T Time 


\section{Introduction}

Radiation activity exists everywhere on the surface of Earth and its interior. Uranium-238, thorium-232 (and their progenies) and potassium-40 are most important sources of radiation. These nuclei are found in any type of rocks, especially in igneous and sedimentary rocks. U-238 decays by ejection an alpha particle to generate daughter radionuclide Th-234 which followed by other decays to produce other radionuclides such as $\mathrm{Ra}-226$ and its progeny $\mathrm{Rn}-222$. $\mathrm{Si}$ milarly, Th-232 disintegrates to produce Rn-228 and followed by other radionuclides [1]. These radionuclides constitute risks by the external exposure to gamma radiation emissions and internally by radon and its progenies. Radon is a human carcinogen, and it is considered the second leading cause of lung cancer [2]. Knowledge of radionuclide distribution is important because it gives helpful information in the observation of natural environmental radioactivity and connected external exposure that resulting from gamma radiation primary based on the geological and geographical conditions and can be seen at various levels in the rocks of each area of the world [3]. The aim of this study is to determine the radionuclides activity concentration of Ra-226, Th-232 and K-40 for igneous and sedimentary rock samples collected from Al-Atawilah (north of Al-Baha region), and to estimate the doses and hazard indices originate from the existence of the natural radionuclides in the surrounding area. Moreover, Ra-226, Th-232 and $\mathrm{K}-40$ activity concentrations were used to simulate and predict the range of decay by using an appropriate program. The results are used to assess the future effect of these radionuclides and evaluate the future of radiation hazards.

\section{Methodology}

\subsection{Sampling and Samples Preparation}

Eighteen igneous rock samples and twelve sedimentary rock samples were collected from Al-Atawilah $\left(20.273351^{\circ} \mathrm{N}, 41.358325^{\circ} \mathrm{E}\right)$, north of Al-Baha region, southeast of Saudi Arabia, Figure 1.

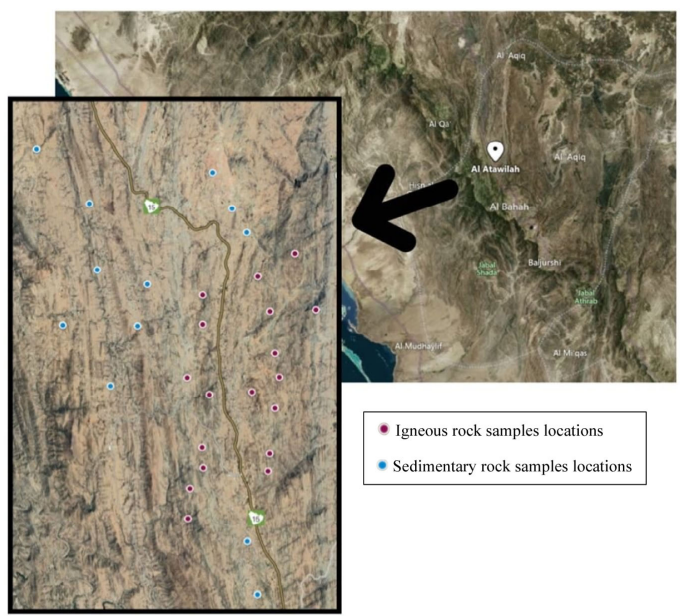

Figure 1. Locations of the igneous and sedimentary rock samples of Al-Atawilah region. 
The samples were collected from the study region at depth $\approx 5 \mathrm{~cm}$, by cracking the rock with hammer after removing a thin layer of the mother rock. Then, the collected samples were dried, pulverized and then sieved through less than $1 \mathrm{~mm}$-mesh size [4]. All crushed sieved rock samples were filled into Polyethylene Marinelli beakers. The samples were pulverized into fine-grained powder for uniform distribution of radon and its decay products and to avert any accumulation in the top [5]. The weight of each sample was recorded and then hermetically sealed from outside using a thick tape for more than a month so as to establish the secular equilibrium between Ra-226 and Th-232 (and their decay products) [6] [7].

\subsection{Measurements Equipment}

Measurement of radionuclides activity concentrations in the rock samples were evaluated by using high-resolution gamma-ray spectrometry system includes hyper-purity closed-end coaxial germanium detector. The detector had resolution of $2 \mathrm{keV}$ at $1332.5 \mathrm{keV}$ of Co-60 and 25\% relative efficiency and peak to Compton ratio of 50:1. The detector is placed in a cylinder-heavy lead shield to minimize the radiation background values. Activity concentration calculations were based on the establishment of secular equilibrium in the measured sample between ${ }^{226} \mathrm{Ra}$ and ${ }^{232} \mathrm{Th}$ and their progenies of smaller lifetime [8]. ${ }^{226} \mathrm{Ra}$ activity concentration was evaluated from the peak energies of $295.2 \mathrm{keV}$ and $351.9 \mathrm{keV}$ at ${ }^{214} \mathrm{~Pb}$ and $609.3 \mathrm{keV}, 1120.28$ and 1764.5 at ${ }^{214} \mathrm{Bi}$. The activity concentration of ${ }^{232} \mathrm{Th}$ was assessed from $\gamma$-ray peaks of $338.3 \mathrm{keV}, 911.1 \mathrm{keV}$ and $968.96 \mathrm{keV}$ at ${ }^{228} \mathrm{Ac}, 238.6 \mathrm{keV}$ at ${ }^{212} \mathrm{~Pb}, 727.3 \mathrm{keV}$ at ${ }^{212} \mathrm{Bi}$ and $583.1 \mathrm{keV}$ and 860.5 at ${ }^{208} \mathrm{Tl}$. The activity concentration of ${ }^{40} \mathrm{~K}$ was determined directly from the $\gamma$-ray line of $1460.8 \mathrm{keV}$ at ${ }^{40} \mathrm{Ar}$, and ${ }^{137} \mathrm{Cs}$ activity concentration was evaluated from peak energy of $661.6 \mathrm{keV}$ at ${ }^{137} \mathrm{Ba}$.

\subsection{Equations for Calculations}

The radionuclide activity concentration $\left(A_{c}\right)$ in the investigated rocks samples were determined in $\mathrm{Bq} \cdot \mathrm{kg}^{-1}$. The activity concentration calculations were carried out using the following formula [9] [10]:

$$
A_{c}=N_{c} / m \beta \varepsilon
$$

where: $N_{c}$ is the net peak area per unit time (second), $m$ is sample mass in $\mathrm{kg}, \varepsilon$ is the detector absolute efficiency at the photo-peak energy and $\beta$ is the branching ratio of gamma radiation.

Radium equivalent $\left(R a_{e q}\right)$ is calculated by applying the following equation [11] [12]:

$$
R a_{e q}\left(\mathrm{~Bq} \cdot \mathrm{kg}^{-1}\right)=C_{R a}+1.43 C_{T h}+0.077 C_{K}
$$

where: $C_{R a}, C_{T h}$ and $C_{K}$ are ${ }^{226} \mathrm{Ra},{ }^{232} \mathrm{Th}$ and ${ }^{40} \mathrm{~K}$ activity concentrations, respectively.

External hazard index $\left(H_{e x}\right)$ can be calculated from the following equation 
[10] [11]:

$$
H_{e x}=C_{R a} / 370+C_{T h} / 259+C_{K} / 4810
$$

To keep the radiation hazard insignificant, the calculated value of the external hazard index must be less than unity [13].

Representative level index $\left(I_{\gamma}\right)$ is determined with following equation [14]:

$$
I_{\gamma}=\left(C_{R a} / 150\right)+\left(C_{T h} / 100\right)+\left(C_{K} / 1500\right)
$$

The absorbed dose rate $\left(D_{R}\right)$ in air at $1 \mathrm{~m}$ overhead the ground level was evaluated from the activity concentrations of the relevant natural radionuclides according to the following equation [15]:

$$
D_{R}\left(\mathrm{nGy} \cdot \mathrm{h}^{-1}\right)=0.462 C_{R a}+0.604 C_{T h}+0.0417 C_{K}
$$

\subsection{Decay Simulation of Natural Radionuclides}

The mean activity concentrations in the rock samples of Al-Atawilah were used to simulate and predict the range of decay. The decay of the radionuclides U-238 (Ra-226), Th-232 and K-40 of the rocks samples were simulated using written MATLAB R2020ascript according to the exponential law of radioactive decay [16]:

$$
A=A_{0} \mathrm{e}^{-\lambda t}
$$

where: $A$ is the change of the radioactive nuclei number with time, $A_{0}$ is the initial activity, $t$ is the time and $\lambda$ is the constant of the decay.

In this study, Forward Different Interpolation Method was applied to reconstruct the activity concentrations of radionuclides. The term $\mathrm{e}^{-\lambda t}$ of the radionuclide decay equation " $A=A_{0} \mathrm{e}^{-\lambda t}$ " ( $\mathrm{n}$ to a $4^{\text {th }}$ order) was used in Taylor polynomial form. The decay factor $\mathrm{e}^{-\lambda t}$ was approximated to a polynomial form by the following analysis for the fourth order:

$$
P_{n}(\lambda t)=P_{n}(z)
$$

Since:

$$
P_{n}(z)=\mathrm{e}^{-\lambda t}=\mathrm{e}^{-z}
$$

this yields the polynomial as:

$$
\begin{aligned}
\mathrm{e}^{-z}=P_{n}(z)= & a_{0}+a_{1}\left(z-z_{0}\right)+a_{2}\left(z-z_{0}\right)\left(z-z_{1}\right) \\
& +a_{3}\left(z-z_{0}\right)\left(z-z_{1}\right)\left(z-z_{2}\right) \\
& +a_{4}\left(z-z_{0}\right)\left(z-z_{1}\right)\left(z-z_{1}\right)\left(z-z_{2}\right)\left(z-z_{3}\right)
\end{aligned}
$$

where

$$
\begin{gathered}
a_{0}=y_{0}=P_{0}\left(z_{0}\right) \\
a_{1}=\left(y_{1}-y_{0}\right) / h=\Delta y_{0} / h \\
a_{2}=\left(y_{2}-2 y_{1}+y_{0}\right) / 2 h^{2}=\Delta^{2} y_{0} / 2 h^{2} \\
a_{3}=\left(y_{3}-3 y_{1}+3 y_{1}-y_{0}\right) / 2 ! h^{3}
\end{gathered}
$$




$$
a_{4}=\left(y_{4}-4 y_{3}+6 y_{2}-4 y_{1}+y_{0}\right) / 4 ! h^{4}
$$

The coefficients $a, b, c$ and $e$ were calculated for the equation (8), and it was used with MATLAB R2020a to simulate the decay of the radionuclides ${ }^{238} \mathrm{U}$, ${ }^{232} \mathrm{Th}$ and ${ }^{40} \mathrm{~K}$ using their half-lives [17].

$$
P_{n}(z)=a z^{4}+b z^{3}+c z^{2}+d z+e
$$

\section{Results and Discussion}

\subsection{Activity Concentrations}

Analytical results for the samples have been applied to evaluate the activity concentration of ${ }^{226} \mathrm{Ra},{ }^{232} \mathrm{Th}$ and ${ }^{40} \mathrm{~K}$, and the artificial radionuclide $\left({ }^{137} \mathrm{Cs}\right)$ in $\mathrm{Bq} \cdot \mathrm{kg}^{-1}$ together with their total uncertainties. The results are presented in Table 1. In the igneous rock samples, the activity concentrations of ${ }^{226} \mathrm{Ra}$ ranged from 5.86 to $17.50 \mathrm{~Bq} \cdot \mathrm{kg}^{-1}$ with average value of $11.00 \mathrm{~Bq} \cdot \mathrm{kg}^{-1}$, ${ }^{232} \mathrm{Th}$ from 21.42 to 5.12 $\mathrm{Bq} \cdot \mathrm{kg}^{-1}$ with average value of $11.50 \mathrm{~Bq} \cdot \mathrm{kg}^{-1}$. For ${ }^{40} \mathrm{~K}$ activity concentrations varied from 328.08 to $4854.00 \mathrm{~Bq} \cdot \mathrm{kg}^{-1}$ with average value of $1172.71 \mathrm{~Bq} \cdot \mathrm{kg}^{-1}$. The concentrations of the fallout nuclide ${ }^{137} \mathrm{Cs}$ varied from 5.63 to $0.90 \mathrm{~Bq} \cdot \mathrm{kg}^{-1}$ and the average value is $1.47 \mathrm{~Bq} \cdot \mathrm{kg}^{-1}$. ${ }^{226} \mathrm{Ra}$ activity concentrations in the sedimentary rock samples varied from 5.23 to $54.85 \mathrm{~Bq} \cdot \mathrm{kg}^{-1}$ with average value of $12.04 \mathrm{~Bq} \cdot \mathrm{kg}^{-1}$. The highest value of ${ }^{232} \mathrm{Th}$ is $61.26 \mathrm{~Bq} \cdot \mathrm{kg}^{-1}$ and lowest value is $5.15 \mathrm{~Bq} \cdot \mathrm{kg}^{-1}$, the average value is $13.18 \mathrm{~Bq} \cdot \mathrm{kg}^{-1} \cdot{ }^{40} \mathrm{~K}$ activity concentrations ranged from 110 $\mathrm{Bq} \cdot \mathrm{kg}^{-1}$ to $6070.75 \mathrm{~Bq} \cdot \mathrm{kg}^{-1}$ with mean value of $1131.36 \mathrm{~Bq} \cdot \mathrm{kg}^{-1}$. The maximum value of ${ }^{137} \mathrm{Cs}$ is 4 and the lowest value is $0.84 \mathrm{~Bq} \cdot \mathrm{kg}^{-1}$, and the average value is $1.60 \mathrm{~Bq} \cdot \mathrm{kg}^{-1} \cdot{ }^{137} \mathrm{Cs}$ radionuclide is found in the most of the studied igneous and sedimentary rocks samples. Radium and Thorium activity concentrations of the studied igneous and sedimentary rocks varied depending on the types of the rocks. However, the average values of ${ }^{226} \mathrm{Ra}$ and ${ }^{232} \mathrm{Th}$ activity concentrations are less than the world average (50 Bq. $\mathrm{kg}^{-1}$ ) reported in UNSCEAR 2008. Potassium activity concentration $\left(C_{K}\right)$ values are higher than recommended value in all igneous rock samples, except for two samples. The mean value of ${ }^{40} \mathrm{~K}$ the igneous rock samples is 2.35 times greater than the acceptable average value of 500 Bq. $\mathrm{kg}^{-1}$ that recommended by UNSCEAR $2008 .{ }^{40} \mathrm{~K}$ is the most important radionuclides identified, it is the extremely abundant natural radionuclide in all igneous rock samples under investigation. The average contribution of ${ }^{40} \mathrm{~K}$ in the igneous rock samples is $98.1 \%$ while the average contributions of ${ }^{226} \mathrm{Ra}$ and ${ }^{232} \mathrm{Th}$ are $0.92 \%$ and $0.96 \%$, respectively.

${ }^{40} \mathrm{~K}$ activity concentration are measured higher than the acceptable value in all the sedimentary rock samples in this study except for four samples. The calculated mean value of ${ }^{40} \mathrm{~K}$ is 2.2 times higher than the recommended value reported in UNSCEAR $2008\left(500 \mathrm{~Bq} \cdot \mathrm{kg}^{-1}\right) .{ }^{40} \mathrm{~K}$ radionuclide is the most significant radionuclide had measured, it is most abundant natural radionuclide in all sedimentary rock samples under studied. The mean contribution of ${ }^{40} \mathrm{~K}$ in the sedimentary rock samples is $97.82 \%$ while the mean contributions of ${ }^{226} \mathrm{Ra}$ and ${ }^{232} \mathrm{Th}$ are $1.04 \%$ and $1.14 \%$, respectively. 
Table 1. Values of activity concentrations, radium equivalent, external hazard index, $\gamma$-ray representative level index and absorbed dose rate, and their minimum, maximum and mean values of the rock samples.

\begin{tabular}{|c|c|c|c|c|c|c|c|c|c|c|c|c|}
\hline \multirow{2}{*}{ Rock type } & \multirow{2}{*}{$\begin{array}{l}\text { Sample } \\
\text { code }\end{array}$} & \multicolumn{4}{|c|}{ Activity Concentration $\left(\mathrm{Bq} \cdot \mathrm{kg}^{-1}\right) \pm \mathrm{SD}^{\mathrm{a}}$} & \multirow{2}{*}{$\begin{array}{c}\mathrm{Ra}_{\mathrm{eq}} \\
\left(\mathrm{Bq} \cdot \mathrm{kg}^{-1}\right)\end{array}$} & \multirow{2}{*}{$H_{e x}$} & \multirow{2}{*}{$I_{\gamma}$} & \multicolumn{4}{|c|}{ Absorbed Dose rate $\left(\mathrm{nGy} \cdot \mathrm{h}^{-1}\right)$} \\
\hline & & ${ }^{226} \mathrm{Ra}$ & ${ }^{232} \mathrm{Th}$ & ${ }^{40} \mathrm{~K}$ & ${ }^{137} \mathrm{Cs}$ & & & & ${ }^{226} \mathrm{Ra}$ & ${ }^{232} \mathrm{Th}$ & ${ }^{40} \mathrm{~K}$ & Total \\
\hline \multirow{18}{*}{ 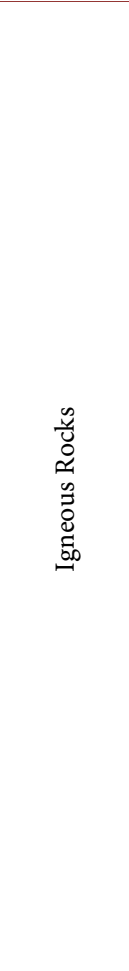 } & RIG001 & $9.56 \pm 1.15$ & $8.36 \pm 1.66$ & $2100.30 \pm 25.40$ & $\mathrm{ND}^{\mathrm{b}}$ & 183.24 & 0.50 & 1.54 & 4.41 & 5.05 & 87.58 & 97.05 \\
\hline & RIG002 & $12.00 \pm 1.26$ & $18.00 \pm 2.84$ & $2400.40 \pm 26.50$ & $3.62 \pm 0.78$ & 222.45 & 0.60 & 1.85 & 5.51 & 10.85 & 100.10 & 116.45 \\
\hline & RIG003 & $12.00 \pm 2.35$ & $10.68 \pm 1.45$ & $867.45 \pm 19.10$ & $2.40 \pm 0.54$ & 94.00 & 0.25 & 0.76 & 5.40 & 6.45 & 36.17 & 48.03 \\
\hline & RIG004 & $11.50 \pm 1.25$ & $14.13 \pm 2.25$ & $1240.50 \pm 21.40$ & ND & 127.21 & 0.34 & 1.04 & 5.30 & 8.53 & 51.73 & 65.57 \\
\hline & RIG005 & $10.07 \pm 1.34$ & $8.83 \pm 2.70$ & $445.70 \pm 16.50$ & $1.50 \pm 0.40$ & 57.02 & 0.15 & 0.45 & 4.65 & 5.33 & 18.58 & 28.57 \\
\hline & RIG006 & $11.60 \pm 1.11$ & $11.50 \pm 1.50$ & $575.46 \pm 17.07$ & $4.00 \pm 0.58$ & 72.34 & 0.20 & 0.57 & 5.35 & 6.95 & 24.00 & 36.30 \\
\hline & RIG007 & $16.05 \pm 1.40$ & $19.10 \pm 3.00$ & $2510.00 \pm 27.10$ & $3.48 \pm 0.72$ & 236.64 & 0.63 & 1.97 & 7.42 & 11.53 & 104.66 & 123.63 \\
\hline & RIG008 & $17.50 \pm 1.42$ & $8.30 \pm 1.67$ & $2895.17 \pm 28.30$ & ND & 252.31 & 0.68 & 2.12 & 8.10 & 5.01 & 120.72 & 133.83 \\
\hline & RIG009 & $17.00 \pm 1.58$ & $19.83 \pm 2.00$ & $2696.45 \pm 27.80$ & ND & 253.00 & 0.68 & 2.11 & 7.85 & 11.98 & 112.44 & 132.27 \\
\hline & RIG010 & $5.86 \pm 1.25$ & $9.32 \pm 2.45$ & $1589.32 \pm 22.83$ & ND & 141.57 & 0.38 & 1.20 & 2.71 & 5.63 & 66.27 & 74.61 \\
\hline & RIG011 & $13.10 \pm 1.48$ & $14.00 \pm 2.00$ & $4854.00 \pm 35.00$ & ND & 406.73 & 1.10 & 3.46 & 6.04 & 8.40 & 202.41 & 216.86 \\
\hline & RIG012 & $15.60 \pm 1.46$ & $21.42 \pm 1.82$ & $2266.58 \pm 26.20$ & $2.44 \pm 0.60$ & 220.75 & 0.60 & 1.82 & 7.20 & 12.94 & 94.51 & 114.65 \\
\hline & RIG013 & $6.88 \pm 1.13$ & $7.26 \pm 1.83$ & $328.08 \pm 15.60$ & ND & 42.53 & 0.11 & 0.33 & 3.17 & 4.38 & 13.68 & 21.25 \\
\hline & RIG014 & $8.27 \pm 1.00$ & $5.12 \pm 1.01$ & $1021.56 \pm 20.30$ & $5.63 \pm 0.63$ & 94.26 & 0.25 & 0.78 & 3.82 & 3.10 & 42.60 & 49.50 \\
\hline & RIG015 & $9.25 \pm 1.34$ & $9.00 \pm 1.55$ & $1066.17 \pm 20.50$ & $0.93 \pm 0.40$ & 104.20 & 0.28 & 0.86 & 4.27 & 5.42 & 44.46 & 54.16 \\
\hline & RIG016 & $7.53 \pm 1.27$ & $7.76 \pm 2.10$ & $1297.30 \pm 21.27$ & $0.90 \pm 0.43$ & 118.52 & 0.32 & 1.00 & 3.48 & 4.68 & 54.10 & 62.26 \\
\hline & RIG017 & $6.53 \pm 1.10$ & $8.31 \pm 1.41$ & $600.00 \pm 17.27$ & $1.60 \pm 0.53$ & 64.60 & 0.17 & 0.52 & 3.01 & 5.02 & 25.01 & 33.05 \\
\hline & RIG018 & $6.18 \pm 1.36$ & $6.14 \pm 2.40$ & $3154.70 \pm 29.43$ & ND & 258.00 & 0.70 & 2.20 & 2.85 & 3.71 & 131.55 & 138.12 \\
\hline \multicolumn{2}{|c|}{ Minimum } & 5.86 & 5.12 & 328.08 & 0.90 & 42.53 & 0.11 & 0.33 & 2.71 & 3.10 & 25.00 & 28.57 \\
\hline \multicolumn{2}{|c|}{ Maximum } & 17.50 & 21.42 & 4854.00 & 5.63 & 406.73 & 1.10 & 3.46 & 8.10 & 12.94 & 202.41 & 216.86 \\
\hline \multicolumn{2}{|c|}{ Mean } & 11.00 & 11.50 & 1172.71 & 1.47 & 163.83 & 0.44 & 1.36 & 5.03 & 7.00 & 74.00 & 86.00 \\
\hline \multirow{12}{*}{ 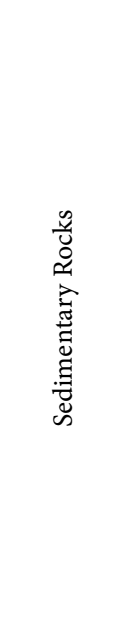 } & RSE019 & $54.85 \pm 2.10$ & $61.26 \pm 6.38$ & $6070.75 \pm 39.50$ & ND & 610.00 & 1.64 & 5.02 & 25.34 & 37.00 & 253.14 & 315.50 \\
\hline & RSE020 & $7.65 \pm 1.12$ & $9.48 \pm 1.16$ & $1366.27 \pm 21.60$ & $4.00 \pm 0.62$ & 126.43 & 0.34 & 1.05 & 3.53 & 5.73 & 56.97 & 66.24 \\
\hline & RSE021 & $10.00 \pm 1.13$ & $8.00 \pm 1.55$ & $1216.20 \pm 20.70$ & $2.87 \pm 0.60$ & 115.00 & 0.30 & 0.95 & 4.60 & 4.82 & 50.71 & 60.13 \\
\hline & RSE022 & $6.00 \pm 1.23$ & $7.47 \pm 1.05$ & $664.68 \pm 17.30$ & $2.34 \pm 0.57$ & 67.84 & 0.18 & 0.55 & 2.76 & 4.51 & 27.71 & 35.00 \\
\hline & RSE023 & $10.67 \pm 1.35$ & $11.36 \pm 1.34$ & $644.40 \pm 17.70$ & ND & 76.54 & 0.20 & 0.61 & 4.93 & 6.86 & 26.87 & 38.66 \\
\hline & RSE024 & $10.20 \pm 1.30$ & $10.55 \pm 1.46$ & $964.78 \pm 19.60$ & $2.30 \pm 0.55$ & 99.57 & 0.26 & 0.81 & 4.71 & 6.37 & 40.23 & 51.33 \\
\hline & RSE025 & $7.78 \pm 1.37$ & $7.12 \pm 1.16$ & $968.84 \pm 19.30$ & ND & 92.56 & 0.25 & 0.76 & 3.60 & 4.30 & 40.40 & 48.30 \\
\hline & RSE026 & $8.58 \pm 1.10$ & $10.71 \pm 2.14$ & $110.00 \pm 13.00$ & $0.84 \pm 0.35$ & 32.37 & 0.08 & 0.23 & 3.96 & 6.47 & 4.58 & 15.02 \\
\hline & RSE027 & $5.58 \quad \pm 1.34$ & $5.15 \pm 1.33$ & $136.26 \pm 14.80$ & $2.00 \pm 0.57$ & 23.45 & 0.06 & 0.18 & 2.58 & 3.11 & 5.68 & 11.37 \\
\hline & RSE028 & $8.03 \pm 1.27$ & $7.90 \pm 1.43$ & $340.25 \pm 15.53$ & $1.30 \pm 0.47$ & 45.51 & 0.12 & 0.36 & 3.71 & 4.76 & 14.18 & 22.66 \\
\hline & RSE029 & $5.23 \pm 1.08$ & $7.38 \pm 1.82$ & $401.08 \pm 16.30$ & $1.95 \pm 0.53$ & 46.67 & 0.12 & 0.37 & 2.41 & 4.46 & 16.72 & 23.60 \\
\hline & RSE030 & $10.00 \pm 1.06$ & $11.86 \pm 1.55$ & $693.07 \pm 18.50$ & $1.57 \pm 0.46$ & 80.30 & 0.20 & 0.64 & 4.60 & 7.16 & 29.00 & 40.67 \\
\hline \multicolumn{2}{|c|}{ Minimum } & 5.23 & 5.15 & 110.00 & 0.84 & 23.45 & 0.06 & 0.18 & 2.41 & 3.11 & 4.58 & 11.37 \\
\hline \multicolumn{2}{|c|}{ Maximum } & 54.85 & 61.26 & 6070.75 & 4.00 & 610.00 & 1.64 & 5.02 & 25.34 & 37.00 & 253.14 & 315.50 \\
\hline \multicolumn{2}{|c|}{ Mean } & 12.04 & 13.18 & 1131.36 & 1.60 & 118.01 & 0.31 & 0.96 & 5.56 & 8.00 & 47.17 & 60.70 \\
\hline \multicolumn{2}{|c|}{ UNSCEAR 2008 [18] } & 50 & 50 & 500 & & 370 & $\leq 1$ & $\leq 1$ & & & & 84 \\
\hline
\end{tabular}

${ }^{a} \mathrm{SD}$ : standard deviation; ${ }^{\mathrm{b}} \mathrm{ND}$ : not determined. 


\subsection{Radiation Hazards}

Table 1 summarized the estimated values of radiation hazard indices (radium equivalent $\left(R a_{e q}\right)$, external hazard index $\left(H_{e x}\right)$, gamma ray representative level index $\left(I_{\gamma}\right)$ and absorbed dose rate $\left(D_{R}\right)$ ) for all igneous and sedimentary rock samples, with the average recommended values reported by UNSCEAR 2008 (370 Bq/kg for $R a_{e q}$ and 1 for $H_{e x}$ and $\left.I_{\gamma}\right)$. In the igneous rock samples, $\left(R a_{e q}\right)$ values are ranged from 42.53 to $406.73 \mathrm{~Bq} \cdot \mathrm{kg}^{-1}$, and the mean value is 163.83 $\mathrm{Bq} \cdot \mathrm{kg}^{-1} .\left(H_{e x}\right)$ are ranged between 0.11 and 1.10 with average value of 0.44 . The lowest value of $\left(I_{\gamma}\right)$ is 0.33 , while the highest value is 3.46 . And the mean value is 1.36. The estimated total absorbed dose rate for the igneous rock samples are varied from 28.57 to $216.86 \mathrm{nGy} \cdot \mathrm{h}^{-1}$, and the mean value is $86 \mathrm{nGy} \cdot \mathrm{h}^{-1}$. The proportions of radionuclides contributions to the total absorbed dose rate in the igneous rock samples are $5.84 \%$ of ${ }^{226} \mathrm{Ra}, 8.13 \%$ of ${ }^{232} \mathrm{Th}$ and $86.04 \%$ of ${ }^{40} \mathrm{~K}$.

In the sedimentary rock samples, the lowermost value of $\left(R a_{e q}\right)$ equal to 23.45 $\mathrm{Bq} \cdot \mathrm{kg}^{-1}$ and the uppermost value is $610 \mathrm{~Bq} \cdot \mathrm{kg}^{-1}$, and the average value is 118.01 $\mathrm{Bq} \cdot \mathrm{kg}^{-1} .\left(H_{e x}\right)$ values are varied between 0.06 and 1.64 respectively, with mean value of 0.31 . The lowest value of $\left(I_{\gamma}\right)$ is 0.18 , where the highest value equal to 5.02 , and the mean value of $\left(I_{\gamma}\right)$ in the sedimentary rock samples is 0.96 . The total absorbed dose rate values are ranged between 11.37 and $315.5 \mathrm{nGy} \cdot \mathrm{h}^{-1}$, with a calculated mean value equal to $60.70 \mathrm{nGy} \cdot \mathrm{h}^{-1}$, and the ratios of radionuclides contributions to the total absorbed dose rate in the sedimentary rock samples are $9.16 \%, 13.18 \%$ and $77.71 \%$ of ${ }^{226} \mathrm{Ra}^{232} \mathrm{Th}$ and ${ }^{40} \mathrm{~K}$, respectively.

\subsection{Natural Radionuclides Decay Simulation of the Rock Samples}

The decay of ${ }^{226} \mathrm{Ra}\left({ }^{238} \mathrm{U}\right.$ equivalent), ${ }^{232} \mathrm{Th}$ and ${ }^{40} \mathrm{~K}$ of the rock samples were predicted over $10^{3}$ years, $10^{6}$ years, $10^{9}$ years and finally over $10^{10}$ years using MATLAB R2020a script based on their present mean activity concentrations. Figures 2-5 display the exponential decay graphs of the natural radionuclides. The mean activity concentrations for all rocks samples under investigation are $11.35 \mathrm{~Bq} \cdot \mathrm{kg}^{-1}$, 12.17 Bq. $\mathrm{kg}^{-1}$ and $1516.17 \mathrm{~Bq} \cdot \mathrm{kg}^{-1}$ for ${ }^{226} \mathrm{Ra},{ }^{232} \mathrm{Th}$ and ${ }^{40} \mathrm{~K}$, respectively. The graphics have been zoomed in to clarify ${ }^{238} \mathrm{U}\left({ }^{226} \mathrm{Ra}\right)$ and ${ }^{232} \mathrm{Th}$ decay curves. The following observations from the simulation outcomes can be indicated as:

1) According to the Equation (6), the decay curves were expected to give an exponential graph, the lines approach zero if the background radiation is ignored.

2) The decay will be almost constant in the several next years in the study area, as the decay was not observed in Figure 2 and Figure 3, this due to the extremely long half-lives of the terrestrial radionuclides, thus the decay that the radionuclides will undergo during thousands or millions years will be insignificant.

3) From Figure 4 and Figure 5, a significant collapse was observed in the decay curve of ${ }^{40} \mathrm{~K}$ compared to ${ }^{232} \mathrm{Th}$ and ${ }^{238} \mathrm{U}\left({ }^{226} \mathrm{Ra}\right)$, this due to its shorter half-life compared to ${ }^{238} \mathrm{U}$ and ${ }^{232} \mathrm{Th}$ half-lives. 

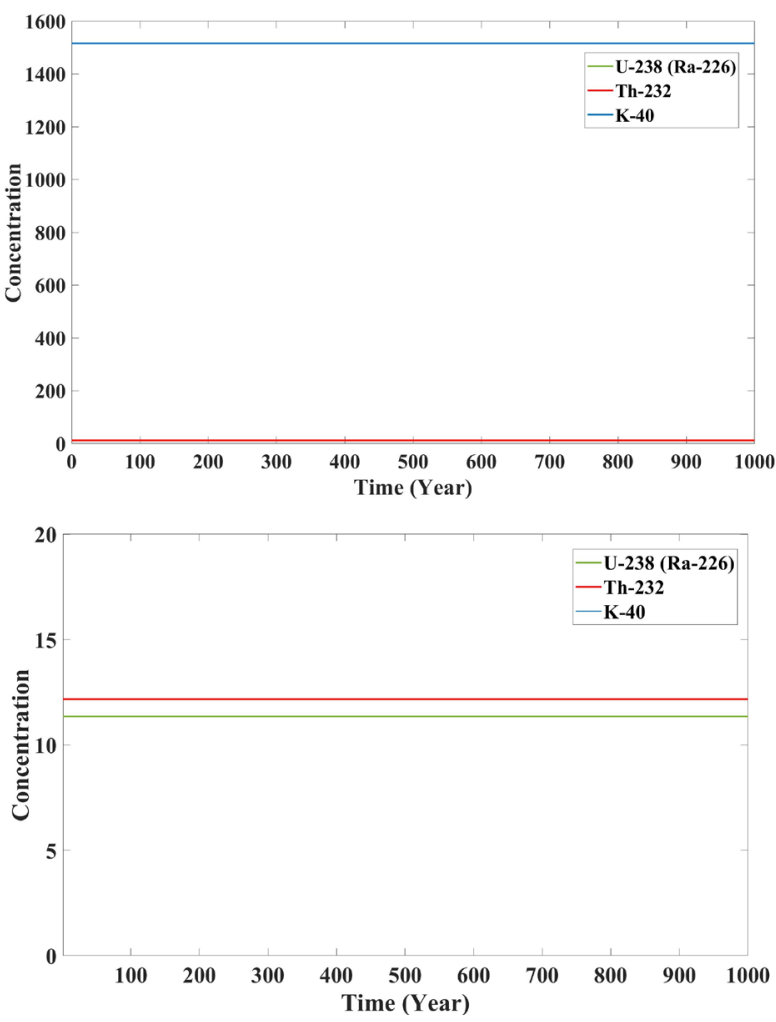

Figure 2. The decay simulation of the natural radionuclides of rock samples over $\times 10^{3}$ years.
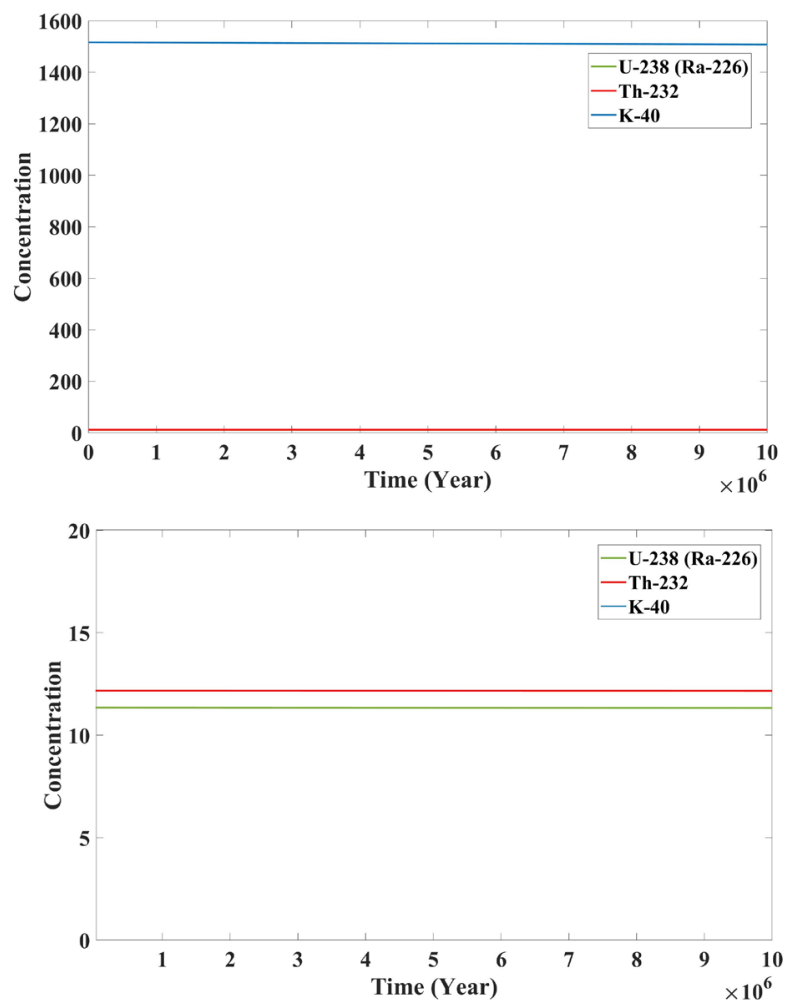

Figure 3. The decay simulation of the natural radionuclides of rock samples over $\times 10^{6}$ years. 

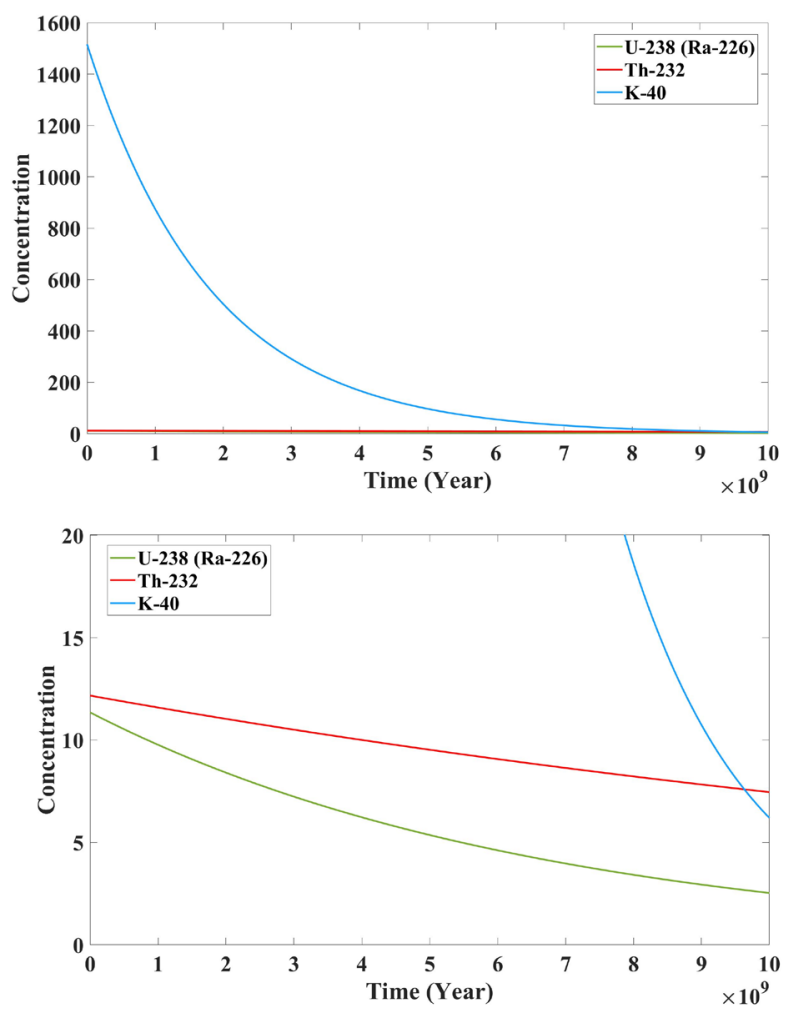

Figure 4. The decay simulation of the natural radionuclides of rock samples over $\times 10^{9}$ years.
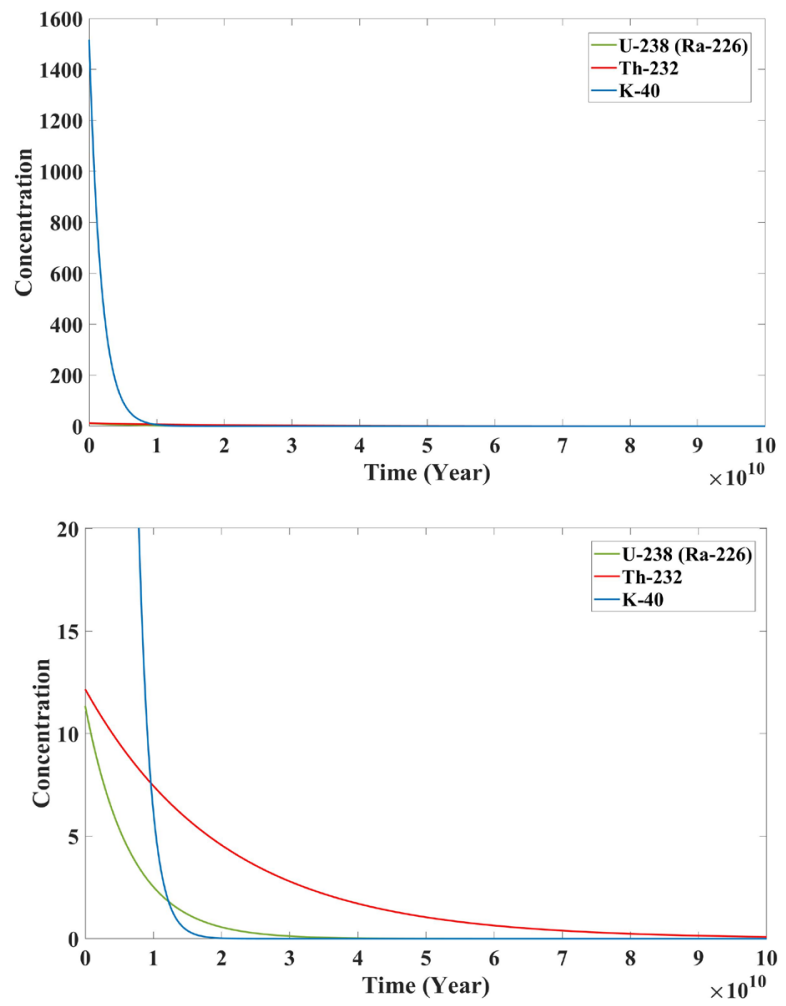

Figure 5. The decay simulation of the natural radionuclides of rock samples over $\times 10^{10}$ years. 
4) This study evaluates the future effect of natural radionuclides on the population of this region and any increase in the concentration of radioactivity should be due to human inputs.

\section{Conclusion}

Gamma-ray spectroscopy of hyper-purity Germanium (HPGe) detector is a good experimental tool for studying levels of the radioactivity in various environmental samples such as rocks. The mean activity concentrations of ${ }^{226} \mathrm{Ra},{ }^{232} \mathrm{Th}$ and ${ }^{40} \mathrm{~K}$ in the igneous rock samples are $11,11.5,1172.71 \mathrm{~Bq} \cdot \mathrm{kg}^{-1}$, respectively. For the sedimentary rock samples, the activity concentrations are found to be $12.04,13.18,1131.36 \mathrm{~Bq} \cdot \mathrm{kg}^{-1}$ for ${ }^{226} \mathrm{Ra},{ }^{232} \mathrm{Th}$ and ${ }^{40} \mathrm{~K}$, respectively. Fallout nuclide $\left({ }^{137} \mathrm{Cs}\right)$ was found in the most of the rock samples under investigation, the low mean values of ${ }^{137} \mathrm{Cs}$ are not of radiologically significant. The calculated mean values of radium equivalent $\left(R a_{e q}\right)$, external hazard index $\left(H_{e x}\right)$, representative level index $\left(I_{\gamma}\right)$ and absorbed dose rate $\left(D_{R}\right)$ are within the suggested limit values, except for a slight increase of $I_{\gamma}$ in igneous rock samples. This study also evaluated the radioactivity levels in the future and their effects on the population of the study region and any increase in the concentration of radioactivity should be due to human inputs. The results of the present study can help us to understand the distribution of natural radionuclides in the environment of Al-Baha region and provide a main map of radioactivity levels in Saudi Arabia.

\section{Conflicts of Interest}

The authors declare no conflicts of interest regarding the publication of this paper.

\section{References}

[1] Omar, M., Hamzah M.S. and Wood, A.K. (2008) Radioactive Disequilibrium and Total Activity Concentration of NORM Waste. Journal of Nuclear Science and Technology, 5, 47-56.

[2] Alharbi, W.R. and Abbady, A.G. (2013) Measurements of Radon Concentrations in Soil and the Extent of Their Impact on the Environment from Al-Qassim, Saudi Arabia. Natural Science, 5, 93-98. https://doi.org/10.4236/ns.2013.51015

[3] Akkurt, I. and Günoğlu, K. (2014) Natural Radioactivity Measurements and Radiation Dose Estimation in Some Sedimentary Rock Samples in Turkey. Science and Technology of Nuclear Installations, 2014, Article ID: 950978. https://doi.org/10.1155/2014/950978

[4] Iaea, I. (1989) Measurement of Radionuclides in Food and the Environment. International Atomic Energy Agency, Technical Report Series, No. 295.

[5] Kerur, B.R., Rajeshwari, T., Sharanabasappa, S.A., Narayani, K., Rekha, A. and Hanumaiah, B. (2010) Radioactivity Levels of Rocks in North Karnataka, India. Indian Journal of Pure \& Applied Physics, 48, 809-812.

[6] Ahmad, N., Jaafar, M. and Alsaffar, M. (2015) Natural Radioactivity in Virgin and Agricultural Soil and its Environmental Implications in Sungai Petani, Kedah, Malaysia. Pollution, 1, 305-313. 
[7] Zubair, M. (2015) Measurement of Natural Radioactivity in Rock Samples Using Gamma Ray Spectrometry. Radiation Protection and Environment, 38, 11-13. https://doi.org/10.4103/0972-0464.162820

[8] Achola, S.O. (2009) Radioactivity and Elemental Analysis of Carbonatite Rocks from Parts of Gwasi Area, South Western Kenya. Doctoral Dissertation, University of Nairobi, Nairobi.

[9] Al-Zahrani, J. (2017) Estimation of Natural Radioactivity in Local and Imported Polished Granite Used as Building Materials in Saudi Arabia. Journal of Radiation Research and Applied Sciences, 10, 241-245. https://doi.org/10.1016/j.jrras.2017.05.001

[10] Younis, H., Qureshi, A.A., Manzoor, S. and Anees, M. (2018) Measurement of Radioactivity in the Granites of Pakistan: A Review. Health Physics, 115, 760-768. https://doi.org/10.1097/HP.0000000000000917

[11] Beretka, J. and Matthew, P. (1985) Natural Radioactivity of Australian Building Materials, Industrial Wastes and By-Products. Health Physics, 48, 87-95. https://doi.org/10.1097/00004032-198501000-00007

[12] Rangaswamy, D., Srilatha, M., Ningappa, C., Srinivasa, E. and Sannappa, J. (2016) Measurement of Natural Radioactivity and Radiation Hazards Assessment in Rock Samples of Ramanagara and Tumkur District, Karnataka, India. Environmental Earth Science, 75, Article No. 373. https://doi.org/10.1007/s12665-015-5195-8

[13] Bavarnegin, E., Moghaddam, M.V. and Fathabadi, N. (2013) Natural Radionuclide and Radiological Assessment of Building Materials in High Background Radiation Areas of Ramsar, Iran. Journal of Medical Physics/Association of Medical Physicists of India, 38, 93-97. https://doi.org/10.4103/0971-6203.111325

[14] Nuclear Energy Agency (1979) Exposure to Radiation from the Natural Radioactive in Building Materials: Report. OECD, Paris.

[15] United Nations Scientific Committee on the Effects of Atomic Radiation (2000) UNSCEAR 2000 Report to the General Assembly, with Scientific Annexes. UNSCEAR, New York.

[16] Krane, K.S. (2019) Modern Physics. John Wiley \& Sons, Hoboken.

[17] Doyi, I., Essumang, D., Dampare, S., Duah, D. and Ahwireng, A. (2017) Evaluation of Radionuclides and Decay Simulation in a Terrestrial Environment for Health Risk Assessment. Scientific reports, 7, Article No. 16537. https://doi.org/10.1038/s41598-017-16659-w

[18] United Nations Scientific Committee on the Effects of Atomic Radiation (2008) UNSCEAR 2008 Report to the General Assembly, with Scientific Annexes. UNSCEAR, New York. 